\title{
O USO DE FONTES HISTÓRICAS EM DISCIPLINAS A DISTÂNCIA
}

\author{
CURITIBA/PR MAIO/2018
}

\author{
RODRIGO OTAVIO DOS SANTOS - UNINTER - rodrigoscama@gmail.com \\ Tipo: Investigação Científica (IC) \\ Natureza: Planejamento de Pesquisa \\ Categoria: Métodos e Tecnologias \\ Setor Educacional: EDUCAÇÃO SUPERIOR
}

\begin{abstract}
RESUMO
O presente artigo pretende, por meio de breve pesquisa exploratória, discutir a questão do uso de fontes históricas em salas de aula na modalidade EAD. Para tanto, buscamos compreender conceitos relativos às fontes históricas e seu uso para a formação de historiadores ou alunos que precisam ter algum tipo de conhecimento que será melhor explicitado por meio de uma ou mais fontes históricas, bem como para o professor que deseja instigar seus alunos por meio de fontes. Assim, primeiramente o artigo versa sobre a internet, para depois explicar metodologia de uso de fontes e principalmente a questão da crítica metodologicamente correta dos vestígios do passado. Em seguida vemos as dificuldades e desafios apresentados pelo uso de fontes históricas no EAD, para concluir explicitando algumas das nossas considerações.
\end{abstract}

Palavras-chave: Ensino a Distância; História; Fontes Históricas 


\section{INTRODUÇÃO}

Com o advento da internet popular, a partir da segunda metade da década de 1990, a humanidade presenciou uma espantosa quantidade de dados sendo distribuídos no ciberespaço, como informa Lemos (2008). Ainda que boa parte desses dados sejam textos e imagens oriundos de redes sociais, como já dizem Policarpo e Santaella (2018), ou mesmo piadas e conteúdo normalmente irrelevante e fugaz, muito podemos utilizar a partir dos grandes bancos de dados de informações disponíveis na rede mundial de computadores.

Nosso intuito aqui é tentar perceber de que forma esses bancos de dados podem ser úteis para a utilização de fontes histórias em sala de aula, e de que forma a internet pode ajudar a potencializar as aulas dos professores de História. Para tanto, primeiramente tentaremos explicar como funcionam as fontes históricas em salas de aulas na modalidade EAD. Lembrando que simplesmente mostrar uma fonte em uma videoaula ou apenas indicar um link e pedir para que os alunos façam o download de uma fonte é muito pouco, e é, em geral, uma exploração inadequada e rasa.

A proposta deste artigo é tentar despertar no professor-pesquisador de História um desejo de utilizar-se de mais fontes em suas aulas a distância e, mais do que isso, instrumentaliza-lo para que ele possa, a partir de sua análise e competência decidir o que é melhor para esta ou aquela turma, para este ou aquele conteúdo.

\section{ETAPAS PARA UTILIZAÇÃO DE FONTES HISTÓRICAS EM EAD}

Isto posto, precisamos dizer que normalmente o uso de fontes históricas em sala de aula - EAD ou presencial - se pauta em três grandes etapas:

A primeira etapa é a Identificação. Com ela, de acordo com Santos (2016), os alunos com apoio do professor - tentam buscar informações dentro e fora do documento apresentado que permitam diversas informações. Assim, o professor pode indicar um link para o acesso ou mesmo disponibilizar, via Ambiente Virtual de Aprendizagem, determinado documento. As primeiras informações identificáveis são a data e o local de origem da fonte. Normalmente - principalmente em documentos - estas são percebidas já na leitura primeira do documento original. Algo como "Rio de Janeiro, 15 de maio de 1932" aparece nos cabeçalhos ou em locais de fácil visualização. Caso esta informação não exista no documento, um esforço para propor estimativas deve ser feito.

A finalidade a que se destinava o documento no contexto de sua produção também 
pode ser descoberta a partir do mesmo procedimento, ou seja, olhando a fonte e dialogando com seu cabeçalho ou estrutura inicial.

Uma vez estabelecidos local, data e finalidade, cabe uma distinção muito interessante para os alunos: o documento apresentado foi confeccionado, na sua origem, com a deliberada intenção de promover um registro futuro para a história ou era meramente um documento técnico, prático, destinado apenas a resolver uma questão pontual? $\mathrm{O}$ professor pode tanto indicar isso na sua aula quanto pode questionar sobre isso nos fóruns.

A partir daí o professor deve contextualizar este documento e então perceber sua inserção na conjuntura em que foi produzido. Cabe ao docente, então, passar aos alunos a ideia de que o documento deve ser sempre entendido como mais um produto da época em que foi gerado. Deve-se pedir aos alunos que estes atentem para as características mais importantes do documento, sempre analisando à luz do contexto geral daquele tópico que estava sendo discutido àquele momento na sala de aula virtual.

É interessante indicar aos alunos que eles podem prestar atenção tanto nas partes muito evidentes do texto, mas também nos silêncios inexplicáveis sobre este ou aquele assunto que deveriam estar na pauta do documento, mas, por algum motivo, não estão. Lembrando sempre que o contexto se estabelece em dois níveis: primeiro o contexto geral do período e, posteriormente, o contexto específico da produção daquela fonte.

A etapa seguinte, seguindo os ensinamentos de Oliveira (2011), é a parte da Interpretação. A partir dela os alunos devem perceber que discursos são proferidos por indivíduos, que atuam como agentes históricos do seu tempo. Assim, deve ficar evidente para os alunos que os textos não são homogêneos, porque cada indivíduo (ou grupo de indivíduos) sente e expressa sua verdade em diferentes níveis econômicos, sociais e políticos. Com isso, cada discurso vira singular, já que cada um é enunciado por um ponto de vista e, recorrendo a Bakhtin (2011), lembramos que nenhum destes processos dialógicos é neutro, ou seja, cada um dos indivíduos possui sua agenda, e sua visão global, já que todo discurso é socialmente determinado.

Estabelecer qual é este determinado ponto de vista pelo qual o autor da fonte histórica fala é, ao mesmo tempo, parte do trabalho de identificação da fonte e também uma etapa da interpretação. Quem escreveu? Por que escreveu? A que interesses atendia? Quais seus objetivos e intenções? Quais valores, doutrinas, valores e ideologias são transportados com o texto? As respostas para tais questões podem ser buscadas em dois níveis: o que diz respeito à forma, ou seja, a retórica, o estilo e a linguagem e 
também no conteúdo, que coloca sentido aos fenômenos históricos, aos indivíduos mencionados, o valor dos eventos, as estratégias etc.

A terceira etapa que Santos (2016) coloca é a Problematização, ou seja, a construção de questionamentos, problemas que as fontes ali postas podem ajudar a responder. Grupos sociais dirigem-se à História para buscar entender como e por que determinado estado de coisas se formou, e também para tentar interpretar as diferentes implicações que a transformação da sociedade ao longo do tempo tem sobre o presente. É por causa desta última informação que podemos afirmar que as possibilidades de problematização de uma fonte não apenas são inúmeras como também se modificam ao longo do tempo. Cabe ao professor então, promover a reflexão com os alunos e, juntos, colocarem questões e criarem diferentes problemáticas para as fontes ali postas e também seu contexto.

Uma vez percebidos as diferentes etapas da utilização da fonte na sala de aula, devemos sempre lembrar do vocabulário. Sempre deve-se atentar para a compreensão dos alunos. Não adianta levar uma cópia da Bill of Rights inglesa se os alunos não sabem inglês. Também não adianta levar algo em português arcaico, pois não haverá compreensão. Em ambos os casos, torna-se necessária a tradução.

No caso dos documentos escritos, há vantagens evidentes, quanto à praticidade. Primeiramente, existe a familiaridade dos alunos com o papel. Tomando o cuidado de traduzir as peças a serem mostradas, os alunos não apresentarão estranhamento em relação à fonte. $\mathrm{Na}$ internet hoje existem milhões de documentos disponíveis para divulgação. Apenas a título de exemplo, atualmente as principais revistas e jornais do país têm na internet todo seu acervo digitalizado, apenas esperando para entrar em sala de aula.

Outra fonte interessantíssima é aquela que pode ser trazida pelos alunos. Pensando em um curso em EAD, estamos claramente imaginando um curso com grandes dimensões geográficas. Assim, podemos imaginar com grande chance de sucesso que uma turma de Ensino a Distância pode facilmente trazer pessoas das mais diferentes regiões do Brasil, gerando assim um microcosmos com inúmeras referências e idiossincrasias próprias de cada local, o que pode, se bem gerenciado, trazer enormes contribuições para todo o grupo.

Do ponto de vista da História, bem como das aulas de História, esta disparidade pode ser muito benéfica a partir do momento que o professor pedir aos alunos que estes apresentem casos de fontes da chamada História Oral. Dito isso, cabe ao docente 
instigar os alunos a fazerem pesquisas com sua própria comunidade. Assim, perguntas simples como "quem é o patrono da cidade" ou "de que forma a cidade se formou" podem trazer inúmeras contribuições para o debate, gerando uma aprendizagem significativa tanto para o aluno pesquisador quanto para os demais alunos que, a partir do relato apresentado, podem fazer a crítica à fonte.

\section{CRÍTICAS ÀS FONTES}

Não importa se texto escrito, audiovisual ou relato, tudo deve ser submetido à crítica. Para Rüsen (2010 p. 123), crítica é

\footnotetext{
A operação metódica que extrai, intersubjetivamente e controlavelmente, informações das manifestações do passado humano acerca do que foi o caso. O conteúdo dessas informações são fatos ou dados: foi o caso em determinado lugar e em determinado tempo (ou não).
}

Cabe então ao historiador e também aos futuros historiadores, averiguar as fontes e usar de sua capacidade analítica para tirar delas a maior quantidade de informações acerca de seu passado e do passado daquilo que estava ao seu redor.

Para o melhor entendimento do professor-leitor deste artigo, cabe aqui um grande parêntesis, a partir da fala de Rüsen: o que é intersubjetividade? Para definirmos isto, primeiro temos que ter a definição anterior, que é a da subjetividade. Esta definição, derivada do cartesianismo estabelece a relação entre sujeito e objeto, e com ela podemos perceber o movimento interno da razão, ou seja, do pensamento humano. Neste caso, a subjetividade é o pensamento humano único, singular, de um indivíduo. Já a intersubjetividade é outra forma de ver a maneira pela qual os pensamentos emergem. Pelo conceito de intersubjetividade, o sentido pleno da experiência humana só pode ser completado a partir da relação comunicacional entre os homens, ou, melhor dizendo, na relação interpessoal dos indivíduos. Assim, diversos pensadores entendem a intersubjetividade como uma espécie de evolução da subjetividade no que tange a conceituar o mundo e experienciar o cotidiano imposto por esta ou aquela realidade.

Quando falamos em extrair intersubjetivamente as informações do passado, estamos então dizendo que não é mais aceitável conhecer apenas o olhar de um homem, de um indivíduo. É necessário chegar à sociedade da forma mais abrangente possível. Os pensamentos de um homem ou de uma mulher são interessantes, sem dúvida, porém, apenas na compreensão da comunidade podemos tentar enxergar melhor o que de fato estava acontecendo naquele local espaço-temporalmente determinado.

Para o docente também é importantíssimo, no momento da análise, ter um ambiente 
controlado. Naturalmente este ambiente controlado não é como o ambiente controlado de um laboratório de biologia de Pasteur que Latour (1983) explica, mas sim uma forma de colocar limites, cercas, para que as ideias dos alunos não saiam do controle. Do contrário, as ideias vão se avolumando e torna-se praticamente impossível fecharmos a pesquisa, o debate e até mesmo a resolução da aula EAD. Além disso, é necessário explicar aos alunos as fronteiras da exequibilidade da pesquisa, e ensiná-los a controlar o que deve e o que não deve ser analisado.

Mesmo em uma aula ministrada a distância, com encontros assíncronos, os fatos ou os dados analisados estarão sempre ligados pela condição espaço-tempo, ou seja, sempre aconteceram em algum lugar em algum momento. Ao exigirmos a crítica das fontes por parte dos estudantes, é importante definirmos muito bem qual é este lugar (ou lugares) e este tempo (ou tempos).

A crítica das fontes fornece à pesquisa um chão seguro, um piso firme para se fixar, e esta característica deve ser reforçada pelo professor o tempo todo, seja em uma aula presencial, seja em uma aula a distância, como coloca Oliveira (2011). Este chão firme é a facticidade do conhecimento histórico, ou seja, a existência - ainda que imprecisa - do fato histórico. É a crítica talvez o principal ponto da objetividade histórica. Sem a crítica às fontes, a História pode facilmente ser tachada de "achismo". A metodologia empregada na análise criteriosa das fontes é o que garante empírica e intersubjetivamente a pesquisa enquanto produto científico.

As fontes passando pelo crivo da crítica promove a depuração das manifestações empíricas do passado, ou seja, separa o joio do trigo, afasta as dissimulações contidas nos textos (como os oficiais, por exemplo, que em geral tem um cunho político muito forte e manifestadamente escondem dados e aumentam outros, de acordo com as posições e interesses do governo em questão) bem como as distorções que podem ocorrer e que normalmente acabam por tornar mais difícil o trabalho de enxergar o passado. Além disso, como sabiamente diz Bloch (2001), a palavra das testemunhas não é digna de crédito apenas por estarem lá e serem testemunhas oculares. Não há por que aceitar os testemunhos históricos apenas por estarem lá. E não estamos dizendo que haja uma tentativa deliberada de ludibriar o futuro historiador. O que acontece é que muitas vezes as pessoas se enganam, esquecem dados importantes ou simplesmente ignoram determinadas coisas que podem ser muito importantes para a pesquisa. Além disso, nem todos os relatos são verídicos e até os vestígios materiais podem ser falsificados e por conta disso, a dúvida sempre foi - e deve continuar sendo um reflexo natural do bom historiador diante de sua fonte. 
Claro que, como continua pontuando o historiador francês, apenas desconfiar também não traz muito benefício para a pesquisa, já que ao desconfiar de tudo e todos, também dificulta a progressão da pesquisa. Bloch (2001) então nos diz que quanto mais regras objetivas tivermos, melhor será a triagem das fontes. E que tais regras continuam a ser implementadas, por cada novo aparato técnico ou nova técnica aprendida ou modificada.

\section{PROBLEMAS E DESAFIOS}

Como a internet é um novo aparato e as aulas ministradas à distância mediadas por computadores são ainda mais novas, cabe explicar ao docente que estas metodologias de usos de fontes em um mundo virtual podem sofrer alguns percalços. Um deles é a intangibilidade da fonte. Ainda que existam inúmeros sites que tragam os documentos digitalizados, não é a mesma coisa que, por exemplo, pegar em um documento original em um museu. Claro que documentos raros nunca seriam disponibilizados em mãos de alunos, mas a simples aura do documento original, tal qual explica Benjamin (1994) em relação à obra de arte provoca uma sensação de empoderamento no aluno-historiador.

Outro forte senão é a diferença destas fontes em diferentes alunos por conta dos aparatos que utilizam para acessar seus AVA. Um aluno que acessa um documento manuscrito (como uma carta do século XVIII) em uma tela de 29 polegadas em um computador, certamente pode apreciar mais coisas que um aluno que está vendo a mesma carta em um telefone celular de apenas 5 polegadas. Ainda que tenhamos as ferramentas de zoom, que aproximam detalhes da fonte, podemos afirmar que há grande diferença entre os tamanhos das telas. Além disso, há diferenças em tipos de tela: Há as mais novas, cuja resolução é muito melhor do que as que foram fabricadas há apenas três ou quatro anos. E não podemos de forma alguma exigir que nossos alunos tenham sempre os equipamentos de última geração.

\section{CONSIDERAÇÕES FINAIS}

Para concluirmos, é importante destacar que o historiador não é nada sem fontes. Aliás, Bloch (2001) diz que não há historiador sem fontes. Assim, é de grande importância que o estudante de História já tenha o contato com as fontes desde o início de seu trajeto nesta disciplina. E cabe ao professor proporcionar estes encontros, seja de forma presencial seja a distância. O contato virtual com as fontes históricas pode, portanto, conferir uma grande intimidade do aprendiz com seu afazer histórico, principalmente se este contato lhe propiciar momentos de crítica, debate e esclarecimento sobre os vestígios do passado. 


\section{REFERÊNCIAS}

BAKHTIN. Mickhail. Estética da criação verbal. São Paulo: WMF, 2011.

BENJAMIN, Walter. Obras Escolhidas: Magia e técnica, arte e política. São Paulo: Brasiliense, 1994.

BLOCH, Marc. Apologia da História. Rio de Janeiro: Zahar, 2001.

LATOUR, Bruno. Give Me a Laboratory and I will Raise the World, in: K. Knorr-Cetina y M. Mulkay (org.), Science Observed: Perspectives on the Social Study of Science, Londres: Sage, 1983.

LEMOS, André. Cibercultura: Tecnologia e vida social na cultura contemporânea. Porto Alegre: Sulina, 2008.

OLIVEIRA, Dennison. Professor-Pesquisador em Educação Histórica. Curitiba: IBPEX, 2011

POLICARPO, Clayton; SANTAELLA, Lúcia. A estética do conhecimento nas redes digitais. In: Revista Dialogia no 28 jan/abr 2018. Disponível em $<$ http://www4.uninove.br/ojs/index.php/dialogia/article/viewFile/8455/3720> acesso em 15/05/18.

RÜSEN. Jörn. Reconstrução do Passado. Brasília: UNB, 2010.

SANTOS, Rodrigo Otávio dos. Fundamentos da Pesquisa Histórica. Curitiba: Intersaberes, 2016. 